\title{
Development and Pilot Application of an Integrated Support Model for Disadvantaged Young Children in Poor Rural China
}

\author{
Liyan Huo $\quad$ Minyi Li \\ Beijing Normal University \\ China
}

\begin{abstract}
As the biggest developing country in the world, China is now tackling the pressing problems of child poverty, whilst facing the increasing aging population at the same time. In August 2009 and April 2010, the China Development Research Foundation (CDRF) officially launched the Project Equal Start: Program of Early Childhood Development in Poor Rural Areas in Qinghai Province and Yunnan Province, which aims at enhancing early childhood development and tackling poverty in poor rural areas. In this article, we described the development the pilot programs' sites, objects and phases, and also evaluated the significant improvement in multiple dimensions such as children's early development, education attainments, and parental involvement. At last, it analysed the CDRF'S pilot programs' policy advocacy, and prospected its influences over how to universalize early childhood development and education in poor rural China.
\end{abstract}

Key words: early childhood development and education, disadvantaged young children, rural China

\section{Introduction}

Child poverty is one of the world's most pressing problems. Even in developed countries, the proportion of children living in poverty remains high. There are $21.9 \%$ of children in household with equivalent incomes below $50 \%$ of the nation median in the United States, compared to $15.4 \%$ in the United

Correspondence concerning this article should be addressed to Minyi Li, Associate professor, Institute for Early Childhood Education Research, Beijing Normal University, No. 19, Xinjiekouai St., Haidian District, Beijing 100875, P.R. China. Electronic mail be sent to minyili@ bnu.edu.cn.
Kingdom (UNICEF, 2005). The situations in developing countries are even complicated. As the world's biggest developing country, China has made remarkable achievements in reducing the rate of poverty in rural areas. China's poverty-stricken rural population has decreased from 94.22 million at the end of 2000 to 26.88 million at the end of 2010, an equivalent to lifting the entire population of France out of poverty in the past decade (Information Office of the State Council, 2011). However, after applying the poverty line of 1 USD per day for expenditure, China's poor population is estimated at about 150 million. $85 \%$ of the population 
are from rural areas, and about $66 \%$ are concentrated in the western region $(\mathrm{Lu}$, 2011). Furthermore, $25.4 \%$ of the poor population, accounting for $19.8 \%$ of the total population, are children under 16 years old (World Bank, 2009). Even worse, young children from poor rural China suffer from non-parental care, malnutrition and non-formal education. According to the World Bank's data in 2008, one-third of the 3-year-olds children were left behind by their migrant parents, and most of them were cared by their grandparents who have lower educational attainment and have less knowledge and information about nutrition, health, and education than the parents. $34 \%$ of 6 -months babies had anaemia in rural China. Roughly $61 \%$ of China's $0-6$ population live in the rural areas, but only $43 \%$ of the total could enrol in rural kindergartens ${ }^{2}$ (World Bank, 2011). How to target the most disadvantaged children is one of the most challenging problems for Chinese government, while facing the increasing aging population at the same time.

\section{The Development of Project Equal Start}

China was the world's leading economy

\footnotetext{
2 In mainland China, preschools have a different name “you er yuan"(幼儿园), which literally means "kindergarten" in Chinese, usually referring to full-day programs serving 3-6 years old children with focus on education and care.
}

from the early 1500s until the early 1800s (Maddison, 2001, 2007). But the country experienced tremendous catastrophes and advanced amidst turbulence in the later two centuries. Even though China has achieved intensive and extensive growth since 1978, it is still a developing country in terms of GDP per capita. Chinese government has adopted different strategies to eliminate poverty in last over 30 years. Since 1984, the government has targeted rural development that emphasized infrastructure building and economic growth. Since 2000, it has established and improved urban and rural social security systems, and started to focus on human capital investment measures. Since 2006, Chinese government has embraced the three pillars components-development-oriented, social security-backed, and human capital strategies to poverty alleviation (Lu, 2011). Human capital strategy has been the prominent approach to poverty reduction, having a wide range of supports with respect to health, education and etc. Since inequality is so deep in this country that the vulnerable children suffering from poverty need an integrated support model to reach their full potentials, which might lay a solid foundation for war on poverty. The central government has implemented new fiscal reform of the free compulsory education since March 2006 through the large transfer payment, exempting tuition fees and textbook fees for all and subsidizing living allowances for poor boarding students. However, early childhood development and education 
has been long neglected with regard to budgetary share. For example, preprimary education only received $1.3 \%$ of the budgetary expenditure in 2008, while the enrolment accounted for $9.3 \%$ of the total (World Bank, 2011). Concerning the gap between rural and the urban development is widening because of a rural-urban dual system, children in poor and rural areas are unable to get access to affordable and quality services for early childhood development and education. Furthermore, young children aged 0-6 are subject to the highest incidence of poverty (World Bank, 2009). In order to promote equality of quality and eliminate the poverty as early as possible, it needs to create an equal start in life for all children, especially in the areas of early childhood development and education for poor and rural children. As a pioneer in promoting policy consultation to render service to the social and economic development of China, the CDRF (China Development Research Foundation) initiated an innovative project to explore a cost-effective model of free early childhood development and education for all children in poor rural China.

\section{Project Sites}

Geography and ethnicity matter in poverty in China. The Southwest and Northwest's shares in the aggregate of incidence of poverty, depth of poverty and severity of poverty are much higher, about $51 \%, 59.6 \%$ and $65.7 \%$ respectively. Furthermore, poverty is most severe in mountainous and minority areas (World Bank, 2009). Given the conditions, Qinghai Province in the Northwest and Yunnan Province in the Southwest were targeted areas. The CDRF worked with two provinces to choose suitable project sites to match the designed goals. In August 2009 and April 2010, the CDRF officially launched the Project Equal Start: Program of Early Childhood Development in Poor Rural Areas in Qinghai Province and Yunnan Province, which has the goal to enhance early childhood development and fight poverty in poor rural areas. Research teams from Beijing Normal University, Chinese Center for Disease Control and Prevention, East China Normal University and Peking University work closely with the CDRF and local governments to develop and evaluate an integrated pilot program to support whole child development and parental involvement.

Project sites Ledu County and Xundian County, share a lot of similarities. Firstly, they are nationally designated poor counties $_{3}$ with relative low rural per capita net income. Secondly, there is a huge multi-ethnic population located in mountainous areas, without accessible infrastructures such as convenient transportation, health care and education

\footnotetext{
3 In 1994, the Chinese government launched a poverty-reduction initiative under the '8-7 Plan' with the major objective of raising percapita income to 500 yuan (in 1990 prices) within seven years. This plan targets 592 designated poverty counties in the country. In 2012, Poverty Alleviation Leading Group Office from the State Council adjusted the list for 592 designated poverty counties.
} 
services. Thirdly, although 5-6 year old children might have one-year preschool education in preschool classes affiliated to local primary schools, most of 3-5 years olds children are left behind. They are almost deprived of early education opportunities, and taken care of by their illiterate grandparents at home, of whom without any knowledge of care and education.

\section{Project Objects}

Chinese Center for Disease Control and Prevention was invited to carry out baseline surveys of nutritional status among 6-24 months infants in two project sites. In terms of health care indicators, Higher anaemia $(57.8 \%$ and $71.7 \%)$, stunting $(6.2 \%$ and $21.7 \%)$ and underweight $(5.7 \%$ and $9.2 \%)$ rates, compared with the national averages (33.9\% in anaemia, $6.4 \%$ in stunting and $4.0 \%$ in underweight) for the rural areas, were found in Ledu County and Xundian County (Lu, 2011). Furthermore, caregivers usually lack of knowledge and information on nutrition and health care. Field investigations also disclosed that 3-5 year-old children in poor mountainous areas are almost in deprivation of the access to kindergartens. Insufficient schools faced a big challenge to accommodate huge population, since there are no qualified kindergartens in remote villages. Baseline surveys on 2-5 years old children's cognitive and social development conducted by Peking University revealed a notably lower performance in Ledu County. Children scored $60 \%$ lower than their urban counterparts in language, cognition and communication skills (CDRF's Task Force, 2011a). The prevalence of selfesteem, shyness, communication difficulties, personality problems were found in field investigations, and most of them do not want to communicate with the outside world, with only simple exchange of dialect language.

Based on the baseline surveys' data and policy advocacy, CDRF has initiated three key objects of the program: healthy newborns, normal nutrition for infants (up to 24 months), and basic early education for 3-5 year-olds.

The program was implemented in Early Childhood Education Centres. The centres usually set up by renovating an abandoned primary classroom or house in a village. ECEC acts as an antipoverty measure, with target goals to improve nutritional conditions of infants and enhance the early education coverage rate with sufficient quality in these areas.

\section{Project Phases}

In accordance with Project objects, the program was divided into three phases, focusing on care and education. The first phase was nutrition improvement for pregnant women and nutritional intervention for 6-24 month-old infants. Free micronutrient supplements were available for pregnant women until the babies were born. Providing free soybased supplement sprinkles (yingyangbao, 营养包) made by Chinese Center for Disease Control and prevention, fortified with micronutrient such as iron and 
Table 1

Pilot programs' coverage in Ledu county and Xundian county (October,2010)

\begin{tabular}{|c|c|c|c|}
\hline \multicolumn{2}{|c|}{ Program } & Ledu County & Xundian County \\
\hline \multirow{3}{*}{$\begin{array}{l}\text { Nutrition } \\
\text { Program }\end{array}$} & Pilot townships & 9 & 4 \\
\hline & 6-24 month-old infants & 1970 & 872 \\
\hline & Pregnant women & 1479 & 615 \\
\hline \multirow{4}{*}{$\begin{array}{c}\text { Early } \\
\text { Childhood } \\
\text { Education } \\
\text { Program }\end{array}$} & Pilot townships & 14 & 4 \\
\hline & Teaching sites & 87 & 71 \\
\hline & 3-5 year-old children & 1479 & 1481 \\
\hline & Volunteer teachers & 52 & 53 \\
\hline
\end{tabular}

zinc, for infants from when they turn 6 months old until they reach 2 years old. Administering physical exams for infants and establishing health records at township hospitals.

The second phase was nutrition education and parental education at Mommy Schools in township hospitals or village clinics, giving training classes and holding participatory activities at mommy schools in towns or villages once or twice a month. Research teams, local doctors, teachers and relevant officers developed a set of training materials for quality control and further development. In order to encourage active engagement, cash allowances were provided to pregnant women attending mommy schools and infant families participating physical exams to alleviate poverty through nutritional intervention.

The third phase was early childhood education for 3-5 year-olds children. Early childhood education centers as teaching sites in mountain villages were established, and volunteers with early education training or teaching experiences were recruited, "trans-village teaching" model was organized to provide easy and free access to early childhood education for children living in mountainous areas unable to receive formal kindergarten education. The research team from Beijing Normal University was responsible for teacher selection and on-site training. Teachers were trained to create a childfriendly environment and use a themebased curriculum inspired by Multiple Intelligences to meet with children's multiple needs. Every volunteer teacher was required to frequently visit one or two teaching sites located in villages and made sure that children from the selected villages were given three-hour lessons three times a week on a rotation basis. By Octorber 2010, with support from local authorities, the CDRF had implemented the pilot programs in 9 villages as control groups in Ledu County, and villages in Xundian county, which has covered 4,936 pregnant women and infants in nutrition prograam and 2.960 3-5 years old children in early childhood education program (Table 1) (CDRF's Task Force, 2011a). 
Table 2

Sample distribution of the interim assessment of CDRF's pilot of early child development and education in Qinghai province

\begin{tabular}{ccccccc}
\hline & $\begin{array}{c}\text { Treatment group } \\
\text { in Ledu County }\end{array}$ & $\begin{array}{c}\text { Control group in } \\
\text { Ledu Conty }\end{array}$ & $\begin{array}{c}\text { Pingan } \\
\text { County }\end{array}$ & $\begin{array}{c}\text { Jiangzha } \\
\text { County }\end{array}$ & $\begin{array}{c}\text { Urban areas in } \\
\text { Qinghai }\end{array}$ & $\begin{array}{c}\text { Effective sample } \\
\text { Size }\end{array}$ \\
\hline $\begin{array}{c}\text { Nutritional } \\
\text { Tests }\end{array}$ & 387 & 240 & 428 & 219 & 209 & 1408 \\
$\begin{array}{c}\text { Educational } \\
\text { Assessments }\end{array}$ & 244 & N/A & 355 & 244 & 182 & 1005 \\
\hline
\end{tabular}

\section{Evaluation}

By September 2011, 3,578 pregnant women received micronutrient supplements and 4,617 6-24 month-old infants had soy-based supplement sprinkles. 61 mommy schools and 211 teaching sites were set up in villages, and 4,632 3-5 year-old children got access to early childhood education offered by 151 volunteer teachers in Ledu County and Xundian County. Within two years, the program of early childhood development has reached more and more disadvantaged children.

For the effective assessment, the CDRF conducted a largescale research evaluation in three counties and one municipality of Qinghai Province in May 2011, working with the Chinese Center for Disease Control and Prevention, East China Normal University, National Population and Family Planning Commission, and World Bank. Considering a representative sample, the research team investigated Haidong District where Ledu County is located, Huangnan Tibetan Autonomous Prefecture and the Provincial Capital, Xining City, covering poor rural areas, pastoral areas and city areas. With stratified sampling, PPS sampling and cluster sampling, 17 townships from Ledu County, Pingan County in Haidong District, Jianzha County in Huangnan Tibetan Autonomous Prefecture were selected to represent the rural areas, county town in Ledu county and two districts in Xining City were chosen to represent the urban areas. Totally, 1519 0-36 month-old infants enrolled in the nutrition tests, and 1023 3-6 year-old children participated in the educational assessments (Table 2). All the caregivers were required to answer relevant questionnaires by interviews.

Based on data collections from a large amount of first-hand materials of nutrition and development conditions of children aged 0-3, and cognitive, linguistic and memory abilities of children aged 3-6 years old in poor western rural areas, CDRF finished an evaluation report about the Intern Assessment of CDRF's Pilot of Early Child Development in Qinghai (CDRF, 2011).

After nutrition intervention, targeted children have improved greatly in the treatment group, decreasing anaemia significantly, stunning, underweight rates (Figure 1). For example, after 20 


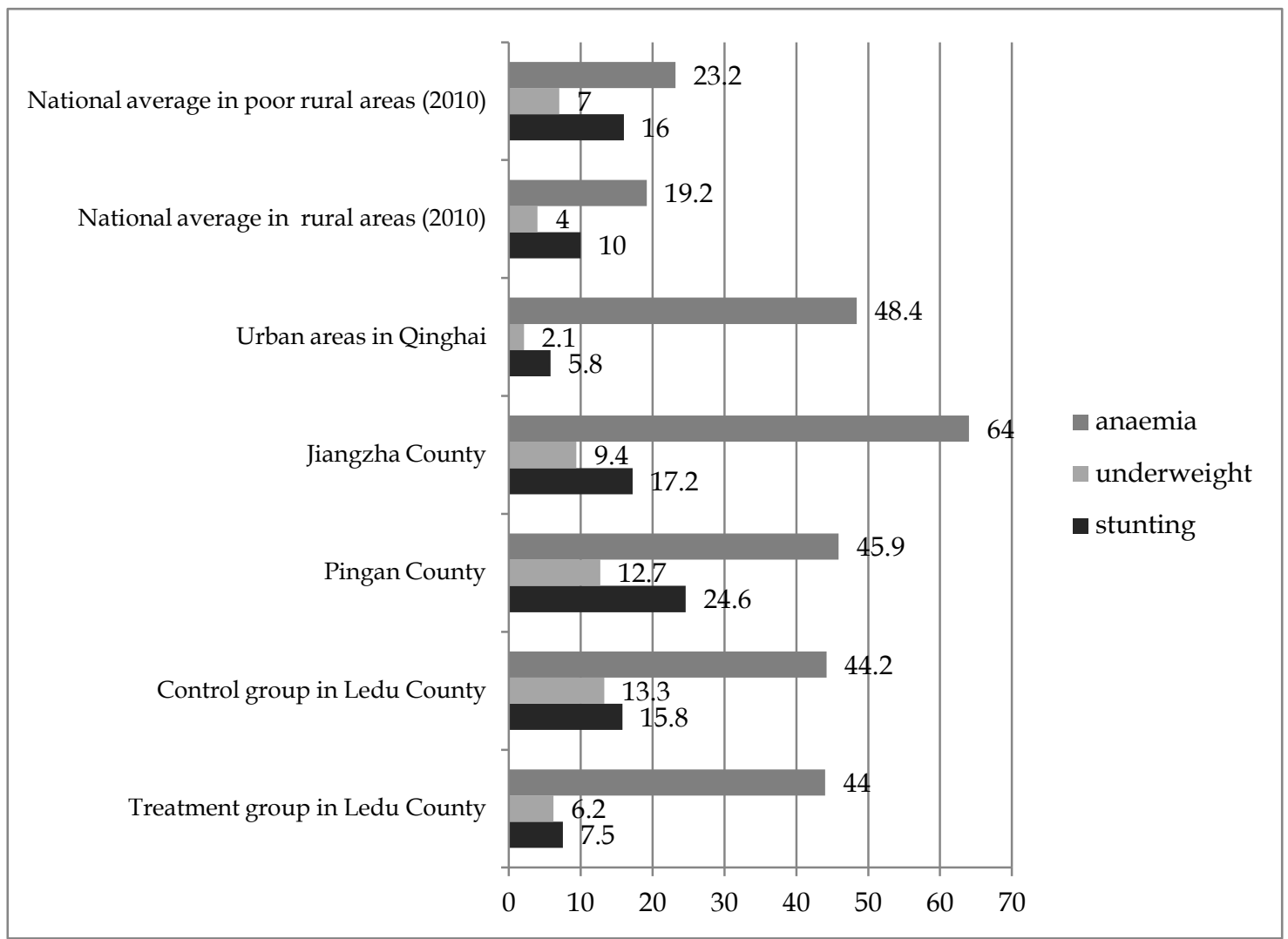

Figure 1. Anaemia, underweight and stunting rates in different areas.

months' intervention, stunning and anaemia rates of 6-24 months-old infants declined noticeably $28.8 \%$ and $12.9 \%$, respectively, when compared to the data in baseline surveys.

In early childhood education program, significant improvement in multiple dimensions such as cognitive development, fine motor skills, problem solving, social development, personal safety and drawing skills etc. through centrebased activities. In baseline surveys for 3-5 year-old children in Ledu County of Qinghai, children's verbal and cognitive developments were on par with only $40 \%$ of their urban kindergarten counterparts.
After 20 months' early education, children's development in language, cognition, motor skills, memory, and social skills have been on par with $93 \%, 86.1 \%$, $87.2 \%, 77 \%$ and $74.4 \%$ of their urban counterparts. Besides, if children attend the free early childhood education from 3-5 years old, they would score 40 or more points totally (CDRF, 2011).

According to 1,242 respondents of the questionnaire, $95 \%$ of caregivers were eager to send their children to the teaching sites, and $79 \%$ of them thought their children had made remarkable achievements and $71 \%$ of the total expressed that their children wish to 
talk about what happened in the school hours (Su, 2011).

The cost-effectiveness analysis helps identify a way to possible policy initiatives across rural poor China. Taking into account geographical factors, the traffic still is the top problem in many remote poor mountainous areas. The transvillage teaching-establishing centres conveniently located close to the child's village homes, organizing volunteers to teach on a rotational basis, and ensuring cost-effective and quality early educational services, could be the best choice in these situations. The trans-village teaching model has ensure the safety of children, and these locally recruited teachers are skilled in the local dialect and Mandarin, also local customs, it might be the most optimal allocation of human resources. Every volunteer teacher was offered 1,200 RMB per month as subsidies, to cover life expense and relevant cost. The total cost of Project Equal Start one year was about 3,000,000 RMB. The cost of offering early childhood development and education was 800 RMB per head per year. An estimated 13.37 million children living in west China, and 8.47 million children of the total aged from 3 to 5 live in villages, and only 30 percent of them have access to kindergartens. Therefore, it will cost the Chinese government 4.7 billion RMB to help educate the 5.9 million children in West China's rural areas, with recruiting 200 thousand teachers (CDRF's Task Force, 2011b).

\section{Conclusion}

Carneiro and Heckman (2003) have highlighted that investment in early childhood yields the highest return to human capital. The World Bank (2011) also encouraged the Chinese government to invest early childhood development and education to break the cycle of poverty and improve future competitiveness (World Bank, 2011). The pilot programs initiated by the CDRF have exerted tremendous influences over using ECEC as an anti-poverty measure and building up competitive human capacities. Since November 17, 2011, Qinghai Province has invested 15,000,000 RMB to scale up CDRF's pilot program and introduced its experience to other 15 counties (Su, 2011). Both Qinghai provincial government and the CDRF reached the consensus that the Program of Early Childhood Development in Poor Rural Areas was a component of China's Grand Western Development Program which aimed at improving people's livelihood. It should be scaled up to cover the whole province. Chen Zhili, vice-chairwoman of the Standing Committee of the National People's Congress and Chairwoman of the All-China Women's Federation, stressed at 2011 International Conference on Early Childhood Development, the Chinese government was capable of sponsoring such programs to enhance early childhood development among the rural population, especially in education and nutrition (Chen, 2011).

Since the Outlines of China's National Plan for Medium- and Long-Term Education 
Reform and Development 2010-2020 reframes early childhood education's landscape, the Chinese government has promised to universalize 3-year early childhood education up to $70 \%$ national coverage by 2020 (State Council, 2010-7-29), increasing government financing as well as investment through various funding resources, and preferring the central and western rural regions. How to reach the most disadvantaged children in poor rural China would still be a high priority and most difficult problem to test the effective governance of central and local governments, which also needs cross-sectional cooperation between NGOs, academic institutions, local authorities and so on.

\section{References}

Carneiro, P. M., \& Heckman, J. J. (2003). Human capital policy (Institute for the Study of Labor (IZA), Discussion Paper No. 821). Retrieved from http://papers.ssrn.com/sol3/papers.c fm?abstract_id $=434544$.

CDRF. (2011，November). 中国发展研究基 金会儿童早期发展项目：青海试点中期 评估 [Interim assessment of CDRF's pilot of early child development and education in Qinghai Province]. Beijing: Author. CDRF's Task Force on the Program of Early Childhood Program in Poor Rural Areas (2011a). 贫困地区儿童早期发展 试点情况 [Introduction to the pilot sites]. Beijing: CDRF.

CDRF's Task Force on the Program of Early Childhood Program in Poor Rural
Areas (2011b). 䏌于在农村普及学前教 育的建议 [How to universalized early childhood education in west rural China]. Beijing: CDRF.

Chen, Z. (2011, November). An address to 2011 International Conference on Early Childhood Development. Paper presented at the 2011 International Conference on Early Childhood Development, Beijing, China.

Han, Y. (2009, October). Practical viewpoints and careful designs: how to make best benefits of program of early childhood development in poor rural areas. Paper presented at the CDRF: International Symposium on Eliminating Poverty Through Early Child Development, Beijing, China.

Information Office of the State Council. (2011, November). Retrieved from http://www.gov.cn/english/official/ 2011-11/16/content_1994729.htm

Lu, M. (2011, February). Poverty eradication in China: A new phase. Retrieved from China Development Research Foundation Web site: http://www.un.org/esa/socdev/ csocd/2011/Lu.pdf

Maddison, A. (2001). The world economy: A millennial perspective. Paris: Organization for Economic Cooperation and Development (OECD).

Maddison, A. (2007). Chinese economic performance in the long run: 960-2030 A.D. (2nd ed.). Paris: Organization for Economic Cooperation and Development (OECD).

UNICEF. (2005). Child poverty in rich countries, 2005 (Innocenti Report Card No. 6). Florence: UNICEF Innocenti Research Centre. 
World Bank. (2009). From poor areas to poor people: China's evolving poverty reduction agenda: An assessment of poverty and inequality in China. Retrieved from http:/ / siteresources.worldbank.org/C HINAEXTN/Resources/318949123909 6143906/China_PA_Report_March_20 09_eng.pdf?bcsi_scan_B90AE85AF6AB 15C6=0\&bcsi_scan_filename $=$ China_P A_Report_March_2009_eng.pdf

State Council (2010, July). Outlines of China's national plan for medium- and long-term education reform and development 2010-2020. Retrieved from http://www.gov. cn/jrzg/201007/29/content_1667143.h tm, 2010-7-29/2011-2-15.

$\mathrm{Su}$, N. (2011, November). To find a new way to early childhood development in Qinghai. Paper presented at the International Conference on Early Childhood Development. Beijing, China.

World Bank. (2011). Early dildhood development and education in China: Breaking the cycle of poverty and improving future competitiveness (Rep. No. 53746-CN). Washington, DC: The International Bank for Reconstruction and Development/the World Bank. 